\title{
Depression in migrants and ethnic minorities
}

\author{
Dinesh Bhugra \& Oyedeji Ayonrinde
}

Abstract Migration and its associated processes can produce considerable stress on those who are migrating as well as on those around them. Depression should be a common sequel of the process, but is not consistently found to be so. This paper reviews the literature and suggests that various vulnerability factors, including culture shock and changed cultural identity, can play a role in the genesis of depression. Clinicians must be aware of patterns of migration and resilience factors in order to plan any intervention strategies. Stresses due to political and economic factors will have differing influences on the mental state of individuals. One possible contribution may be a discrepancy between aspiration and achievement, which can result in poor self-esteem, leading to depression.

Migration is the process by which individuals move from one place of residence to another, usually for permanent or semi-permanent periods. The causation or the purpose of migration can be economic, social, political, medical or recreational. This movement occurs across different cultural regions and nation states and even within the same state, and it can place the individual under considerable stress. However, the process can be made more manageable and less traumatic by such factors as adequate preparation and social support, along with acceptance by the new culture. Whether individuals travel alone or with family, how the new country welcomes them, their legal status and economic factors all play a role in their adjustment to migration.

People moving within the same culture can also experience stress and feelings of alienation, for example those moving from rural hamlets to large cities. The resulting changes in environment and social support can act as pathogens and the stress (following the stress diathesis model) can increase the likelihood of mental illness. The ideological commitments of individuals to the migration as well as their personality traits need to be understood in the context of migration. Coupled with personality traits are beliefs and attitudes related to the individuals' own culture and their individual aspirations and role performance.

Personality factors lead to a number of stressrelated illnesses. Eysenck (1990) argued that there is sufficient evidence to show that personality factors and stress can lead to feelings of helplessness and hopelessness and finally to depression. In schizophrenia it has been argued that schizotypal personality disorder is associated with migration and subsequent psychosis, but no similar model has been identified for depression in migrants. It is possible that some personalities may be more prone to loss, and dealing with loss may produce depression in vulnerable individuals. Table 1 shows both vulnerability and protective factors related to migration and depression.

Symptoms of depression such as guilt, shame and loss of libido have been shown to vary across cultures (for an overview see Bhugra, 1996). Murphy et al (1967) reported that psychiatrists in 30 countries found varying prevalence of depressive symptoms such as identified fatigue, loss of appetite, loss of sexual interest, weight loss and self-accusatory ideas. The symptoms listed are largely biological. In a fivecentre cross-cultural study, Jablensky et al (1981) found that the core symptoms of depression are sadness, joylessness, anxiety, tension, lack of energy, loss of interest, poor concentration and ideas of insufficiency, inadequacy and worthlessness.

Because the presence and expression of guilt, somatic symptoms and shame in migrants can depend on their culture of origin, depressive manifestations can be overlooked (Bhugra, 2003).

\section{Prevalence of depression}

Most epidemiological studies have used European or North American assessment instruments, which might not identify cases of depression if it does not appear in the standard Western form. The findings of epidemiological studies among migrant groups

Dinesh Bhugra is Professor of Mental Health and Cultural Diversity and heads the Section of Cultural Psychiatry at the Institute of Psychiatry (Health Services Research Department, PO Box 25, De Crespigny Park, London SE5 8AF, UK. E-mail: d.bhugra@iop.kcl.ac.uk). He has published widely in the field of cultural psychiatry, spirituality, sexual dysfunction and diversity. Oyedeji Ayonrinde is a consultant psychiatrist for the South London and Maudsley NHS Trust. His research interests include the role of racial life events and explanatory models in West Africans. 
Table 1 Aetiological model of common mental disorders and migration: vulnerability factors predispose individuals to common mental disorders after migration

Vulnerability factors
Pre-migration
Biological and psychological factors
Social skills deficit
Forced migration
Persecution
Migration
Negative life events
Bereavement
Post-migration
Culture shock
Culture conflict
Discrepancy between achievement and expectation

are equivocal, to say the least. Some studies have demonstrated high rates of common mental disorders in migrant groups (Krupinski, 1967; Kimura et al, 1975). Cochrane (1977) reported that rates of admission to psychiatric hospitals in England and Wales were nearly twice as high among immigrants compared with native groups. After standardisation for age and gender, studies showed much higher admission rates for Irish and West Indian immigrants than for those from India or Pakistan.

Cochrane (1983) subsequently attributed some of the discrepancy in these rates to selective migration, ambivalent relationships and adjustment to culture. Kuo (1976), from the USA, recommended that the role of social isolation, culture shock, goal-striving stress and culture change must be understood in the aetiology of psychological distress. Data on increased rates of common mental disorders among foreign students prompted Ward (1967) to identify a 'foreign student syndrome', which is characterised by non-specific somatic complaints, a passive withdrawn interaction style and an unkempt appearance. He further suggested that these students were also more likely to seek help for physical complaints. Others have reported similar findings (Schild, 1962; Hopkins et al, 1975; Still (1961), cited in Furnham, 1988). Although these findings are old, they are still important. In a study of higher education students in the UK published in 1961 and cited by Furnham (1988), Still observed that only $14 \%$ of British students had psychological problems, compared with $28 \%$ of Iraqi, Iranian and Nigerian students, $22 \%$ of Turkish and Egyptian students and $18 \%$ of students from the Indian subcontinent. Babiker et al (1980) noted that increased rates of medical consultations and symptoms were associated with greater distance from country/culture of origin, and they reported that students who were 'culturally distant' used health services as an approachable haven.
Protective factors

Psychological factors such as resilience

Higher socio-economic status

Voluntary migration

Preparation and adequate run-in time

Strong cultural and ethnic identity

Social support and social networks

Resilience

Social support

More recent studies have confirmed some, but not all, of these findings. The variations in results may be due to different or better methods and may also reflect different interactions between migrants and their new community. In a community sample in Britain, Nazroo (1997) observed that weekly prevalence of depressive neurosis was $2.7 \%$ for White males and $4.8 \%$ for White females. For the Irish respective rates were $5.8 \%$ and $6.8 \%$, and for the African-Caribbeans they were $5.6 \%$ and $6.4 \%$. However, the rates for Indians were $2.5 \%$ and $3.2 \%$ respectively, and for Pakistanis they were $3.8 \%$ and $2.9 \%$. Bangladeshi males reported a prevalence of only $1.6 \%$ and females $2.2 \%$. These diagnoses were made using the Clinical Interview Schedule Revised Version. Interestingly, Nazroo's conclusions were that migrants had lower rates of depression, except for the Pakistani groups. Those who were fluent in English reported the same rates as their British counterparts. If this were taken as a proxy measure for acculturation, it would appear that morbidity was at the same level as in the White British community. The data thus show mixed results. It would appear that migration produces stresses, but that as time goes by the stresses of the act of migration are replaced by the stresses of living in an alien culture. Therefore, the stage at which data are collected can affect results.

Data from the EMPIRIC study (Sproston \& Nazroo, 2002), which focused on the main ethnic groups in England, showed that the Irish group had the highest prevalence of common mental disorders (although only $10 \%$ of Irish men with any ICD-10 diagnosis met criteria for a depressive episode) and that the differences across ethnic groups were not statistically significant. Among the Indian and Pakistani groups, common mental disorders were more prevalent in the women than in the men. However, rates were also high among those who were born in England or migrated here at an early age; this might 
be related to the problems of culture conflict (see Acculturation below).

The three stages of migration (pre-migration, the migration itself and post-migration), although in theory discrete, are not always so in practice. The pre- and post-migration stages last for varying periods. The key pathoprotective or pathoprovocative factors in the genesis of depression and common mental disorders are listed in Table 1.

Bochner (1986) suggests that two modes of cultural contact govern the reaction of people to unfamiliar cultures: adjustment to and reflective learning of the new culture. Individuals exposed to another culture (be it by cross-border or within-country migration) may reject their culture of origin, reject the new culture and militantly retreat into their own culture (exaggerated deculturation) or vacillate between the two cultures (marginal syndrome). Furthermore, they might not adhere rigidly to a single option. It might be hypothesised that there would be exaggerated levels of depression among those who are marginalised, but data for this observation are lacking. Taft (1986) recommends that adjustments, national identity, cultural competence, social absorption and role socialisation all need to be identified and studied in migrant populations.

\section{Aetiological factors}

Furnham \& Bochner (1986) highlighted eight theoretical constructs for adjustment following the process of migration: movement as loss; fatalism; selective migration; expectations; negative life events; social support; social-skills deficit; and a clash of values with the new culture. Some of these might cause depression (e.g. loss, negative life events), whereas others (e.g. social-skills deficit) might simply be associated with depression. We do not propose to discuss them all here. Theoretically, migrants who have lost a number of support factors might be more prone to depression, but the data are not very robust.

\section{Acculturation}

Acculturation is the process by which a minority group assimilates cultural values and beliefs of a majority community. The minority group's adaptation to the majority culture's customs, values and language can be voluntary or forced. Acculturation arouses strong feelings, especially if it is forced. In addition, the contact between the two groups can lead to assimilation, integration, rejection or deculturation. Each of these can have different effects on individuals' personal and social functioning.

Culture shock might be defined as sudden unpleasant feelings that violate an individual's expectations of the new culture and cause them value their own culture negatively. Oberg (1960) identified six aspects of culture shock: strain; a sense of loss or feelings of deprivation; rejection by members of the new culture; role expectation and role confusion; surprise, anxiety and indignation; and feelings of impotence. Furnham (1988) points out that, although others have emphasised different aspects, these six are useful core concepts. Bock (1970) defines culture shock as an emotional reaction to an inability to understand, control and predict behaviour, which appears to be a basic human need. This lack of familiarity may extend to other aspects of functioning such as language, etiquette, food, clothes and climate.

Culture shock can thus be seen as a stress reaction arising from the uncertainty of important physical and psychological rewards. Migrants may therefore remain confused, anxious, apathetic or angry until a level of adjustment is reached. Culture shock may be seen as a transitional experience and also as essential for self-development and personal growth. However, business executives and film stars with several places of residence around the globe and ease of movement are less likely to face culture shock than is an economic migrant. Thus, social class and having a financial 'cushion' might also influence stress responses.

Culture conflict refers to the sense of tension experienced by people from a minority culture. This is much more common for the children of immigrant parents, when the parents' culture and values compete with the majority culture in which the children spend a significant part of the day. This conflict can contribute to a further sense of alienation and isolation, where the children find themselves 'belonging' to neither the majority nor the minority culture.

Both culture shock and culture conflict can cause depression among migrants, probably by interacting with the personality traits of individuals.

Clinicians should be aware of culture shock and have ready a strategy for dealing with it. This might include a focused psychotherapeutic intervention to address the aftermath of the experience. After investigating an individual's cultural identity, the clinician should have an idea of that person's resilience, social support and other protective factors that can be used in treatment planning.

\section{Cognitions}

The cognitive schemas of depression in migrants and ethnic minorities require study. The standard model of the depressive triad - 'I am a failure, the world is a horrible place and the future is bleak' - might not apply universally. Notions of the self and 'I-ness' too will vary across cultures. In sociocentric societies, 


\section{Box 1 Assessing depression in migrants}

- Assess sadness, joylessness, hopelessness, lack of energy, poor concentration

- Look for biological symptoms such as loss of sleep and libido, and variations of appetite

- Assess the reasons for migration, preparation and the actual act of migrating

- Ascertain aspirations and achievements

- Ascertain social support and peer group contacts

- Assess negative life events, feelings of loss and grief

- Assess self-esteem and self-confidence

- Assess whether any social skills deficit is present

- Assess the degree of culture shock

- Assess cultural identity

the individual self may be subsumed in the kinship, family and society. Migration might cause individuals to reconsider, and even change, their notions of the self, which might cause additional stress.

If the individual's model of depression is different or non-medical or non-psychological then it might not fit with standard Western diagnostic models or classificatory categories. The cognitive schema of refugees and political asylum-seekers may contain realistic components of persecution. Such paranoid or persecutory thoughts might further contribute to social withdrawal and a sense of despair and alienation. Time elapsed since migration is another factor that should be taken into consideration. The period immediately after migration is likely to prove a vulnerable time, as is the period 5-7 years later, when individuals have settled down but not fulfilled their aspirations (Bhugra, 2003).

Gilbert \& Allan (1998) propose that, among cognitive factors for depression, social rank, defeat and a sense of entrapment (which is linked with learned helplessness) are important. If the pathway to flight is blocked for social or personal reasons the sense of entrapment may be more significant in the aetiology of depression. Arrested flight involves suppression of explorative behaviour, submissive postures, isolation and severely restricted movement, all of which can be experienced by immigrants at various times.

Having an external locus of control (when the individual feels that external forces or events such as chance, fate or the stars are causing their behaviour or actions) has been shown to be related to poor mental health and a lack of adaptation (Furnham \& Bochner, 1986). However, it is likely that individuals who accept their 'fate' also accept their stresses. This might explain lower than expected rates of reported mental distress among migrants from the Indian subcontinent, among whom belief in karma, fate or the stars is quite prevalent.

\section{Selective migration}

The hypothesis of selective migration of vulnerable individuals predicts that those who are prone to depression tend to migrate. Although studies have shown a wide variation in prevalence rates of depression in different countries (Simon et al, 2002), it is unlikely that current strict immigration laws allow vulnerable individuals to move freely.

\section{Achievements and expectations}

Mismatched aspirations and achievements can also produce stress, which can be related to the onset or genesis of depression. Expectations of the new country in terms of both personal and social gains (prestige in particular) must be matched by achievement if the individual is to function well. If achievements do not match aspirations, individuals are open to low mood, a sense of alienation and, more importantly, a sense of failure - all of which can trigger depression. It is possible that economic migrants will have heightened expectations of social mobility, which are more likely to contribute to a striving for success that might not be matched by achievement. The discrepancy might contribute to poor self-esteem, which in itself might not cause depression but joins cumulative stressors such as racial discrimination.

In assessing the presence of depression in migrants (Box 1) it is important that clinicians establish whether mismatched aspirations and achievements might be creating stress (Box 2).

The clinician can address the discrepancy between a patient's aspirations and achievements by encouraging the individual to look at these in different ways, for example by looking at realistic situations and thinking of even small achievements in a positive light.

\section{Box 2 Aspirations and achievements}

The following questions determine patients' aspirations and achievements :

- What had you achieved before you migrated?

- What level did you think you would reach in the field of ...?

- Have you done so?

- If not, how far do you think you have to go?

- Do you feel let down that you have not done so?

- Do you feel content that you have done so? 


\section{Conclusions}

Not all migrants develop depression. Both personal vulnerabilities and the experiences of migration contribute to its genesis and perpetuation. Culture shock and cultural identity are both involved. Clinicians must be aware of the reasons for migration, social support, models or explanations of depression and how help is sought. Migrants may give different emphasis to different symptoms. The clinician must take into account social, cultural and individual factors. Causative and associative factors of depression should be assessed in the context of the migration itself. Our discussion of the factors that can affect depression in migrants is not exhaustive: see Bhugra (2003) for a fuller consideration. However, we have highlighted areas in the lives of ethnic minority and migrant groups that we believe to be of significance.

\section{References}

Babiker, I., Cox, J. \& Miller, P. (1980) The measurement of cultural distance and its relationship to medical consultations, symptomatology and examination performance of overseas students at Edinburgh University. Social Psychiatry and Psychiatric Epidemiology, 15, 109-116.

Bhugra, D. (1996) Depression across cultures. Primary Care Psychiatry, 2, 153-165.

Bhugra, D. (2003) Migration and depression. Acta Psychiatrica Scandinavica Supplementum, 418, 67-73.

Bochner, S. (1986) Coping with unfamiliar cultures. Australian Journal of Psychology, 38, 347-358.

Bock, P. (ed.) (1970) Culture Shock: A Reader in Modern Cultural Anthropology. New York: Knopf.

Cochrane, R. (1977) Mental illness in immigrants to England and Wales. Social Psychiatry, 12, 25-35.

Cochrane, R. (1983) The Social Causation of Mental Illness. London: Longman.

Eysenck, H. (1990) The prediction of death from cancer by means of personality stress questionnaire. Perceptual and Motor Skills, 72, 216-218.

Furnham, A. (1988) Adjustment of sojourners. In Cross-Cultural Adaptation (eds Y. Y. Kim \& W. B. Gudykunst). Newbury, CA: Sage.

Furnham, A. \& Bochner, S. (1986) Culture Shock. London: Routledge.

Gilbert, P. \& Allan, S. (1998) The role of defeat and entrapment (arrested flight) in depression: an exploration of an evolutionary view. Psychological Medicine, 28, 585-598.

Hopkins, J., Malleson, N. \& Sarroff, I. (1975) Some nonintellectual correlates of success and failure among university students.British Journal of Sociology, 9, 25-36.

Jablensky, A., Sartorius, N., Gulbinat, W., et al (1982) Characteristics of depressive patients contacting psychiatric services in four cultures. A report from the who collaborative study on the assessment of depressive disorders. Acta Psychiatrica Scandinavica, 63, 367-383.

Kimura, S. D., Mikolashek, P. \& Kirk, S. (1975) Madness in paradise: psychiatric crises among newcomers in Honolulu. Hawaii Medical Journal, 34, 275-278.

Krupinski, J. (1967) Sociological aspects of mental ill health in migrants. Social Science and Medicine, 1, 267-281.

Kuo, W. (1976) Theories of migration and mental health. Social Science and Medicine, 10, 297-306.

Murphy, H. B. M., Wittkower, E. D. \& Chance, N. (1967) Crosscultural inquiry into the symptomatology of depression: preliminary report. International Journal of Social Psychiatry, 13, 6-15.

Nazroo, J. (1997) Ethnicity and Mental Health. London: PSI.

Oberg, K. (1960) Culture shock: adjustment to new culture environments. Practical Anthropology, 7, 177-182.
Schild, E. (1962) The foreign student, as a stranger, learning the norms of host cultures. Journal of Social Issues, 18, 41-54.

Simon, G., Goldberg, D., Vonkorff, M., et al (2002) Understanding cross-national differences in depression prevalence. Psychological Medicine, 32, 585-594.

Sproston, K. \& Nazroo, J. (2002) EMPIRIC Report: Survey Carried out on Behalf of the Department of Health by the National Centre for Social Research. http://www.doh.gov.uk/public/empiric

Taft, R. (1986) Methodological considerations in the study of immigrant adaptations in Australia. Australian Journal of Psychology, 38, 339-346.

Ward, E. (1967) Some observations of the underlying dynamics of conflict in a foreign student. Journal of the American College of Health, 10, 430-440.

\section{Multiple choice questions}

\author{
1 Migration can be due to the following reasons: \\ a economic \\ b political \\ c voluntary \\ d repatriation \\ e educational.
}

2 Epidemiological studies of depression show:

a consistently high rates among all migrant groups

b consistently high rates among female migrants

c higher rates among English speakers

$\mathrm{d}$ higher rates among White females than White males

e lower rates among African-Caribbean females than African-Caribbean males.

3 Factors causing depression among migrants include: a loss

b increased social support

c deprivation of specific objects

d culture shock

e altered role expectations.

\section{Culture conflict is related to:}

a conflict between two cultures when an individual is caught between the two

$b$ a sense of alienation

c a sense of achievement

d feeling of belonging

e depression.

5 Among migrants, cognitive schemas that lead to depression include:

a persecution

$b$ entrapment

c arrested flight

d having an external locus of control

e feelings of guilt and shame.

\section{MCQ answers}

\begin{tabular}{|c|c|c|c|}
\hline 1 & 2 & 3 & 4 \\
\hline a $\mathrm{T}$ & a F & a $\mathrm{T}$ & a $\mathrm{T}$ \\
\hline $\mathrm{b} \quad \mathrm{T}$ & b F & $b \quad F$ & b $\mathrm{T}$ \\
\hline c $\mathrm{T}$ & c $\mathrm{T}$ & c $\mathrm{T}$ & c F \\
\hline $\mathrm{T}$ & d $\mathrm{T}$ & $\mathrm{d} T$ & d F \\
\hline $\mathrm{T}$ & e F & e $\mathrm{T}$ & e $\mathrm{T}$ \\
\hline
\end{tabular}

